\title{
Percutaneous closure of subannular rupture following transcatheter aortic valve implantation
}

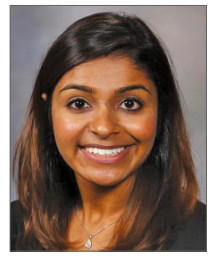

Saumya Shah ${ }^{1 *}, \mathrm{BS}$; Elad Maor², MD, PhD; David L. Joyce ${ }^{3}, \mathrm{MD}$; Charanjit S. Rihal², MD

1. Mayo Clinic School of Medicine, Rochester, MN, USA; 2. Department of Cardiology, Mayo Clinic, Rochester, MN, USA;

3. Department of Cardiovascular Surgery, Mayo Clinic, Rochester, MN, USA

This paper also includes supplementary data published online at: http://www.pcronline.com/eurointervention/128th_issue/247

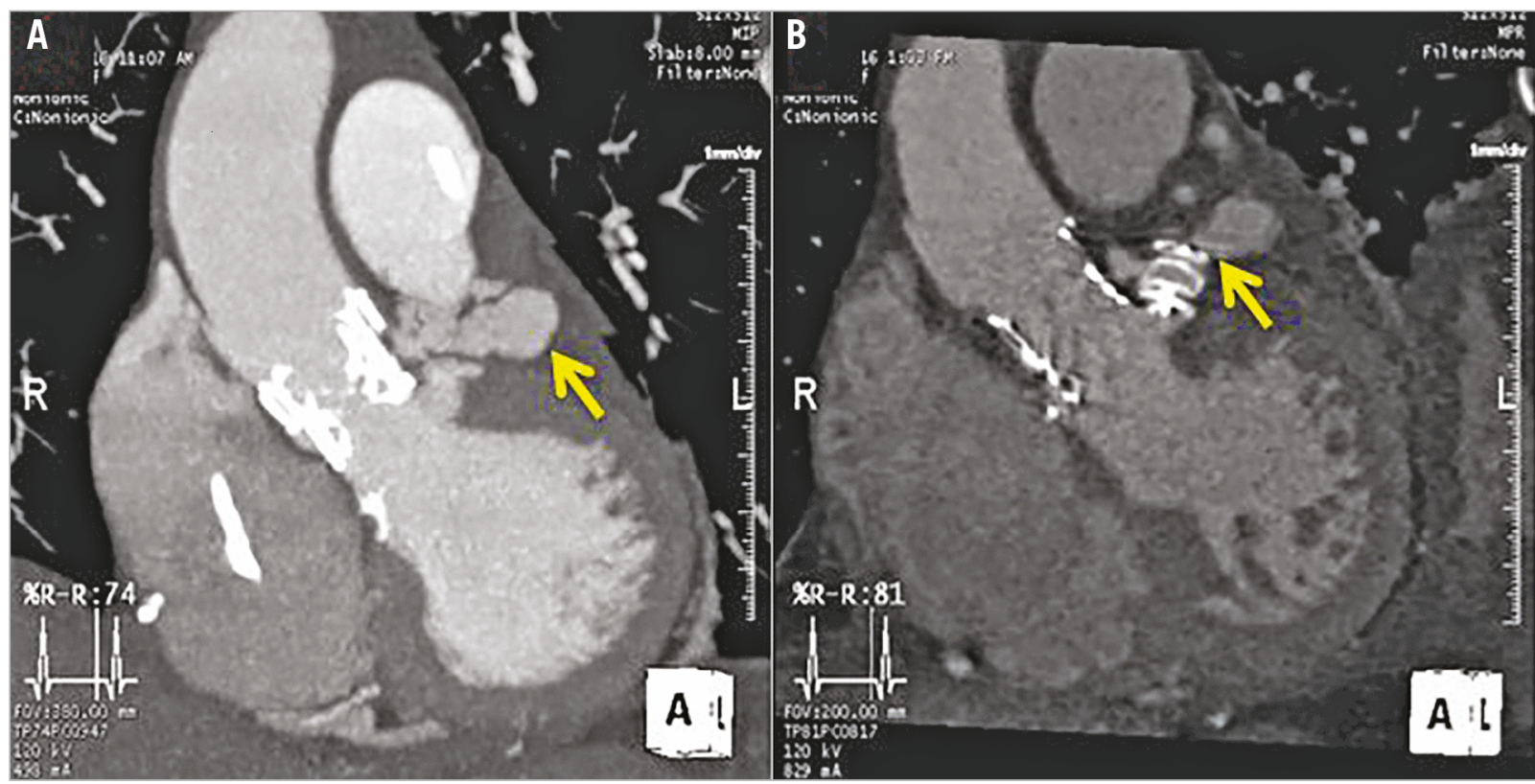

*Corresponding author: Department of Cardiology, Mayo Clinic, 200 1st Street SW, Rochester, MN 55905, USA. E-mail:rihal@mayo.edu 
Aortic annulus rupture is a rare, lethal complication of transcatheter aortic valve implantation (TAVI) ${ }^{1}$, which can develop into a left ventricular pseudoaneurysm ${ }^{2}$. Here we describe the percutaneous management of a patient in whom a left ventricular outflow tract (LVOT) pseudoaneurysm developed following TAVI.

A 79-year-old female with a history of hypertension, hyperlipidaemia, peripheral vascular disease, and lung adenocarcinoma presented with severe symptomatic calcific aortic stenosis (AS) (mean gradient $43 \mathrm{mmHg}$, aortic valve area $0.83 \mathrm{~cm}^{2}$ ). Due to the intermediate STS score of $3.45 \%$ and anticipated lung malignancy resection surgery, TAVI was recommended by the cardiac team. Chest computed tomography (CT) revealed an aortic annulus area of $5.1 \mathrm{~cm}^{2}$ with a perimeter of $83 \mathrm{~mm}$, and an LVOT area of $3.35 \mathrm{~cm}^{2}$ with a perimeter of $69 \mathrm{~mm}$. Based on these measurements, a $26 \mathrm{~mm}$ Edwards SAPIEN 3 bioprosthesis (Edwards Lifesciences, Irvine, CA, USA) that was $1.8 \%$ oversized at the aortic annulus and $>30 \%$ oversized at the LVOT was implanted using a transfemoral approach (Moving image 1). Upon deployment of the valve, the patient became haemodynamically unstable due to annular rupture at the level of the LVOT complicated by acute tamponade (Moving image 2). Emergent pericardiocentesis was performed with drainage of $200 \mathrm{cc}$ of blood. As the patient became haemodynamically stable, she was transferred to the CCU for monitoring.

Next day, transoesophageal echocardiography (TEE) revealed a $32 \times 15 \mathrm{~mm}$ LVOT pseudoaneurysm anterior to the left main extending laterally from the aortic root, following the course of the left anterior descending artery (Panel A, Moving image 3). A percutaneous approach was chosen based on high risk of open repair. After placement of a $6 \mathrm{Fr}$ sheath in the right femoral artery, a left ventricular angiogram demonstrated persistent rupture of the LVOT below the newly placed valve. The neck of the pseudoaneurysm was successfully engaged with an Amplatz left (AL) 0.75 guide. A 12 mm AMPLATZER ${ }^{\text {TM }}$ Vascular Plug II (St. Jude Medical, St. Paul, MN, USA) was deployed at the neck of the pseudoaneurysm and secured according to multiple tug tests (Moving image 4). TEE prior to discharge revealed a secure AMPLATZER plug and wellfunctioning aortic bioprosthesis. CT consistently showed reduction of the pseudoaneurysm to $19 \times 15 \mathrm{~mm}$ with reduced contrast opacification (Panel B). A follow-up CT scan four weeks later showed a re-enlargement of the pseudoaneurysm to $41 \times 18 \mathrm{~mm}$, leading to an open heart aortic valve replacement $\left(19 \mathrm{~mm}\right.$ bovine Trifecta ${ }^{\mathrm{TM}}$ implant; St. Jude Medical) and pericardial bovine patch placement for complete closure of the pseudoaneurysm.

The failure of the percutaneous approach may be explained by the small size of the selected AMPLATZER plug, which provided only partial occlusion of the neck. Persistent flow into the pseudoaneurysm may have contributed to its re-enlargement. Open heart surgery for pseudoaneurysm closure in the TAVI population is especially challenging due to the high-risk nature of this patient population, and thus a percutaneous approach may be a feasible option $^{3}$. Further development and refinement of percutaneous approaches are needed.

\section{Conflict of interest statement}

The authors have no conflicts of interest to declare.

\section{References}

1. Girdauskas E, Owais T, Fey B, Kuntze F, Lauer B, Borger M, Conradi L, Reichenspurner H, Kuntze T. Subannular perforation of left ventricular outflow tract associated with transcatheter valve implantation: pathophysiological background and clinical implications. Eur J Cardiothorac Surg. 2017;51:91-6.

2. Barbanti M, Yang TH, Rodès Cabau J, Tamburino C, Wood DA, Jilaihawi H, Blanke P, Makkar RR, Latib A, Colombo A, Tarantini G, Raju R, Binder RK, Nguyen G, Freeman M, Ribeiro HB, Kapadia S, Min J, Feuchtner G, Gurtvich R, Alqoofi F, Pelletier M, Ussia GP, Napodano M, de Brito FS Jr, Kodali S, Norgaard BL, Hansson NC, Pache G, Canovas SJ, Zhang H, Leon MB, Webb JG, Leipsic J. Anatomical and procedural features associated with aortic root rupture during balloon-expandable transcatheter aortic valve replacement. Circulation. 2013;128: 244-53.

3. Frances C, Romero A, Grady D. Left ventricular pseudoaneurysm. J Am Coll Cardiol. 1998;32:557-61.

\section{Supplementary data}

Moving image 1. A $26 \mathrm{~mm}$ Edwards SAPIEN 3 transcatheter aortic valve bioprosthesis was implanted using a transfemoral approach within the aortic annulus.

Moving image 2. Annular rupture complicated by acute tamponade upon deployment of the valve.

Moving image 3. A $32 \times 15 \mathrm{~mm}$ LVOT pseudoaneurysm anterior to the left main extending laterally from the aortic root and following the course of the left anterior descending artery.

Moving image 4. Closure of pseudoaneurysm via percutaneous placement of a $12 \mathrm{~mm}$ AMPLATZER Vascular Plug II.

The supplementary data are published online at:

http://www.pcronline.com/

eurointervention/128th_issue/247 